\title{
A ZONAL NAVIER-STOKES METHODOLOGY FOR FLOW SIMULATION ABOUT A COMPLETE AIRCRAFT
}

\author{
Jolen Flores
}

\begin{abstract}
The thin-layer, Reynolds-averaged, Navier-Stokes equations are used to simulate the transonic viscous flow about the complete F-16A fighter aircraft. These computations demonstrate how computational fluid dynamics (CFD) can be used to simulate turbulent viscous flow about realistic aircraft geometries. A zonal grid approach is used to provide adequate viscous grid clustering on all aircraft surfaces. Zonal grids extend inside the F-16A inlet and up to the compressor face while power on conditions are modeled by employing a zonal grid extending from the exhaust nozzle to the far field. Computations are compared with existing experimental data and are in fair agreement. Computations for the F-16A in side slip are also presented.
\end{abstract}

Applied Computational Fluids Branch

NASA Ames Research Center

Moffett Field, CA. 94035

Presentation at NASA OAST CFD CONFERENCE

March 7-9, 1989

NASA Ames Research Center 

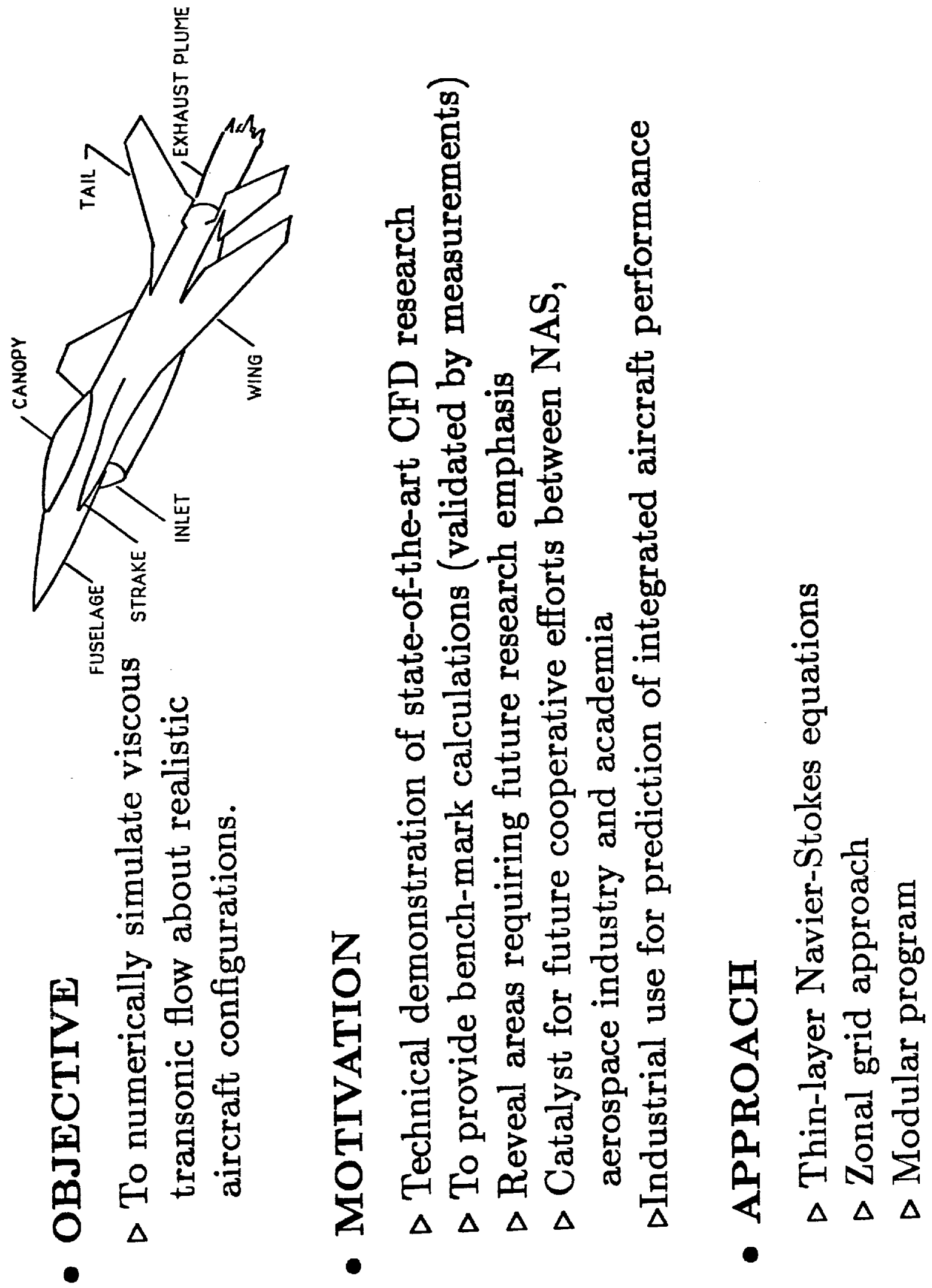


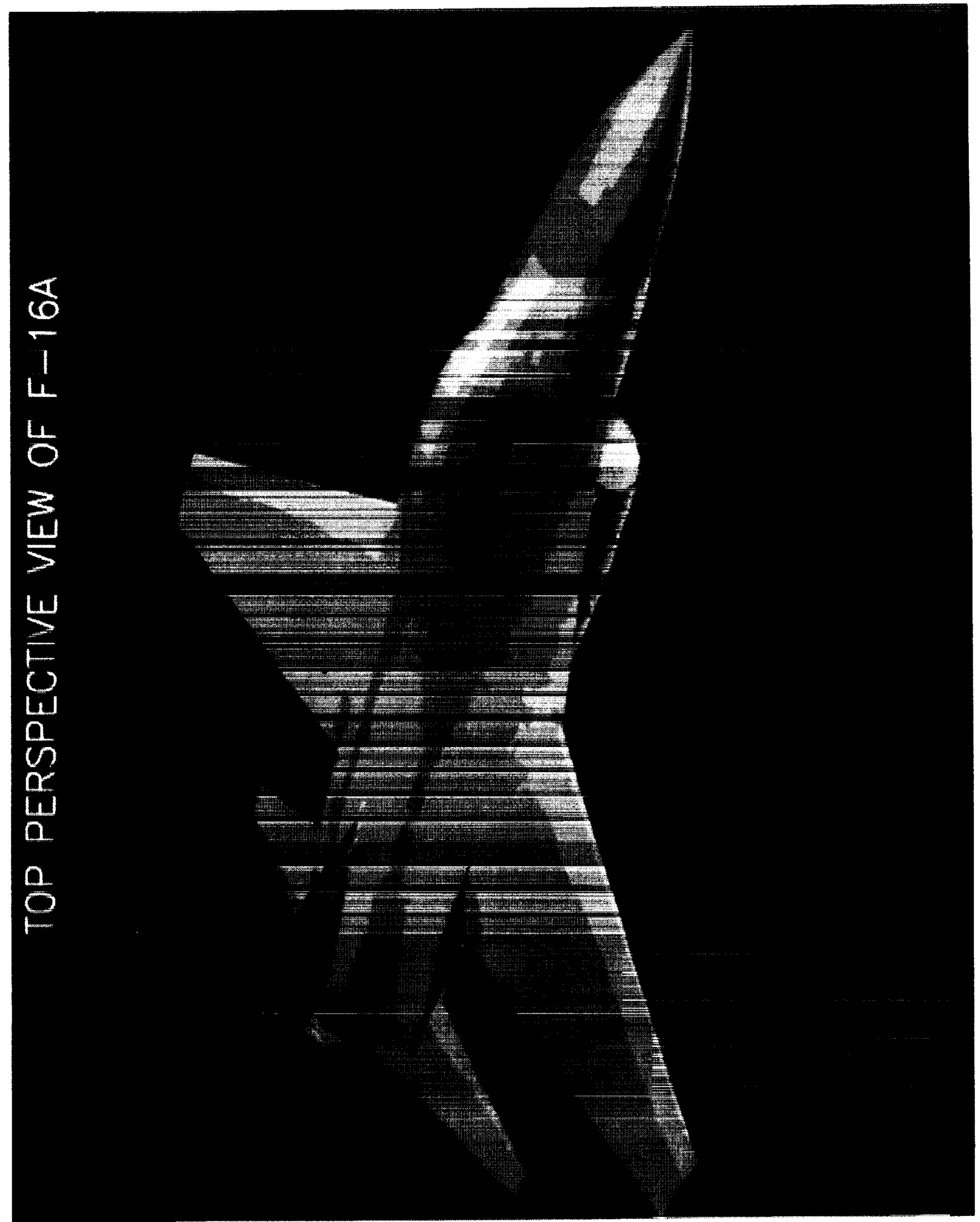




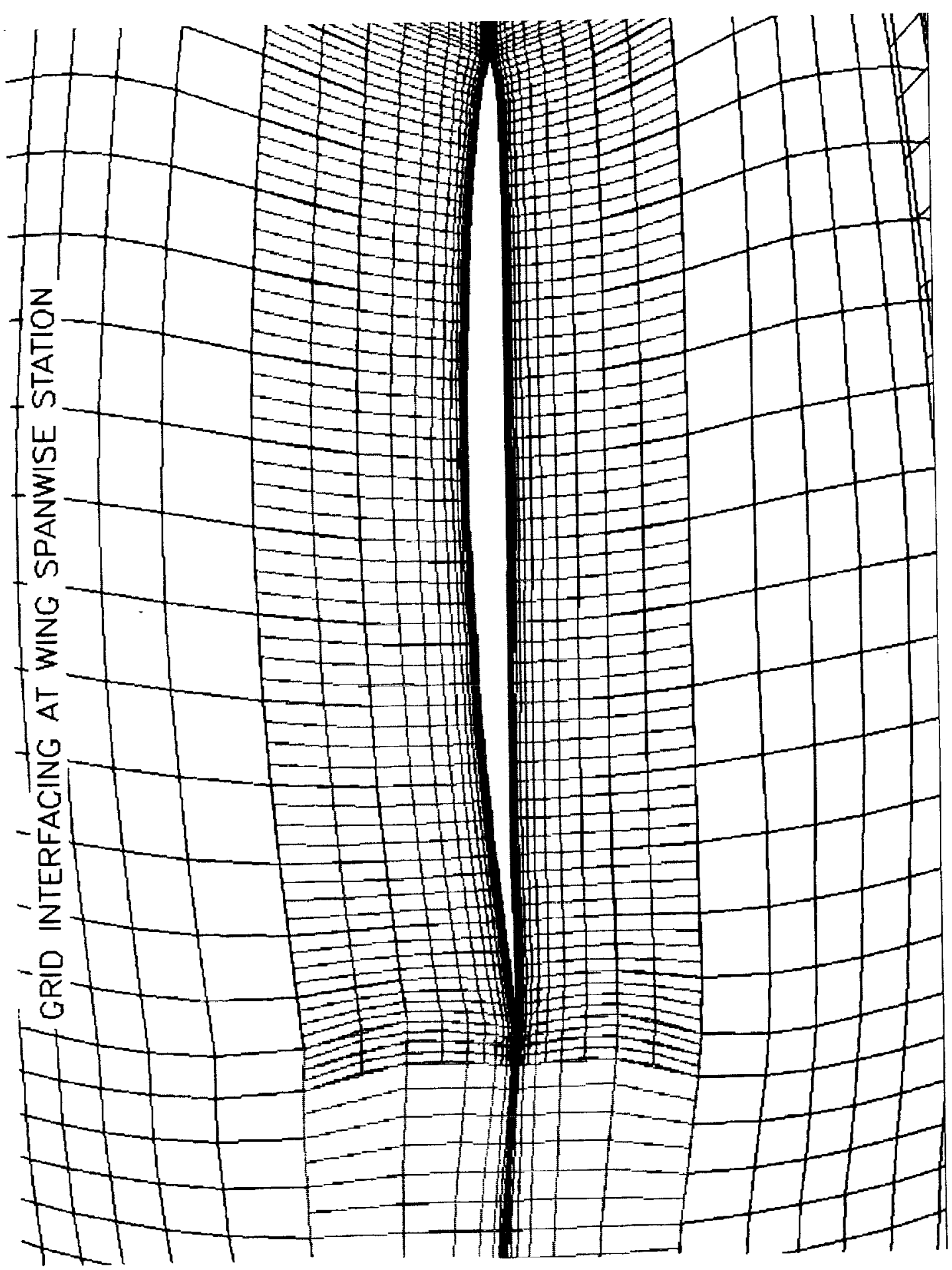




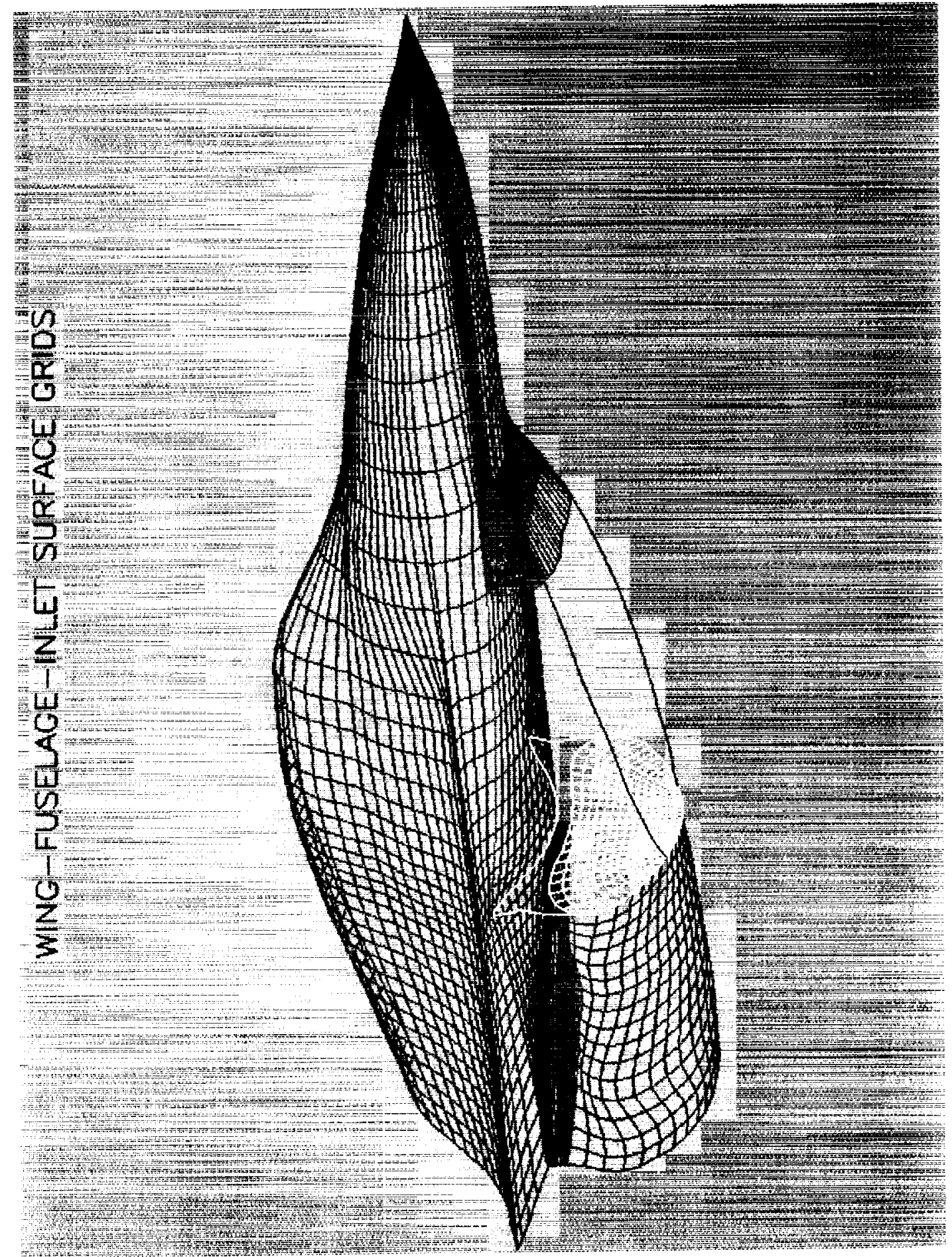




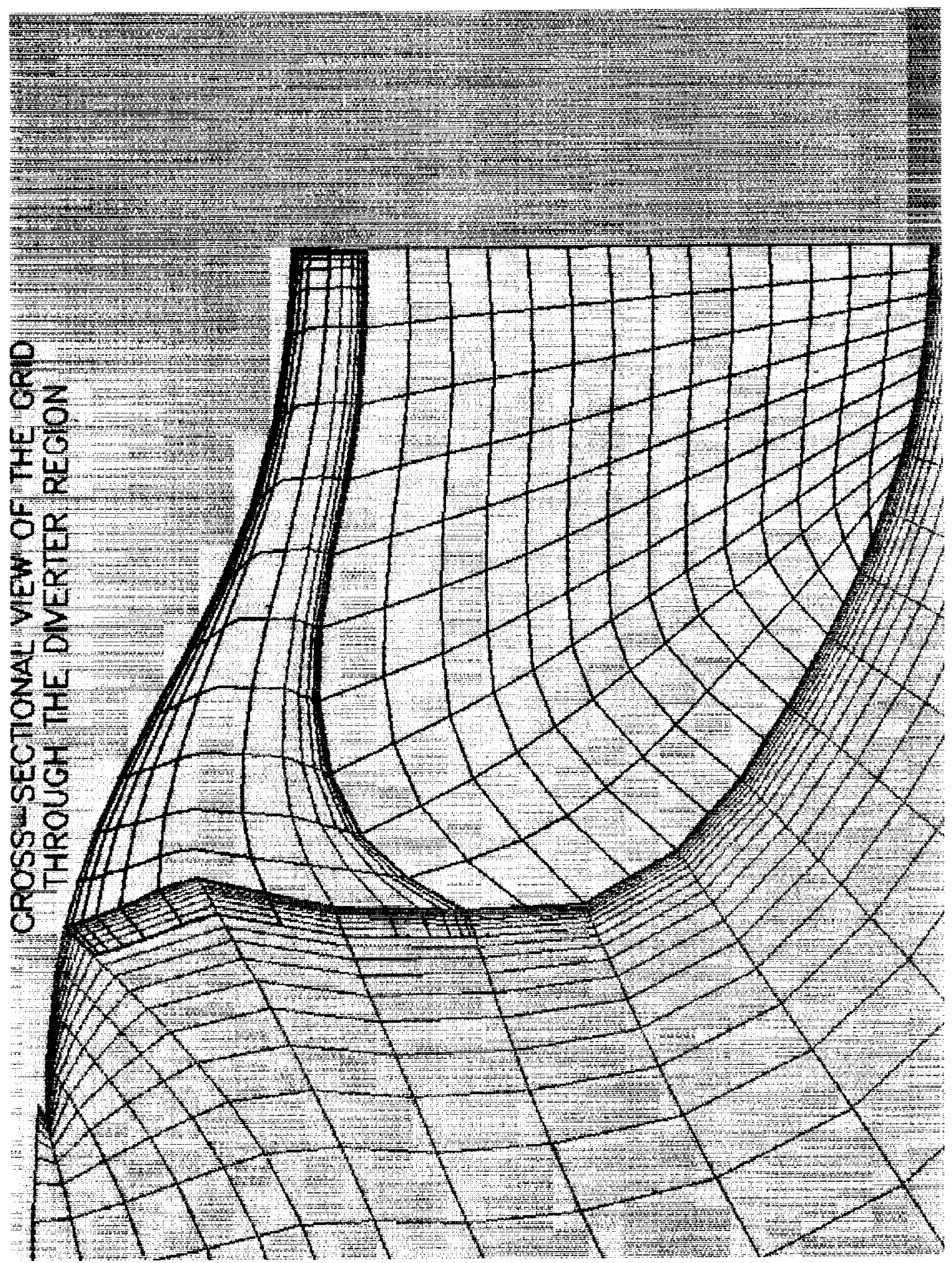



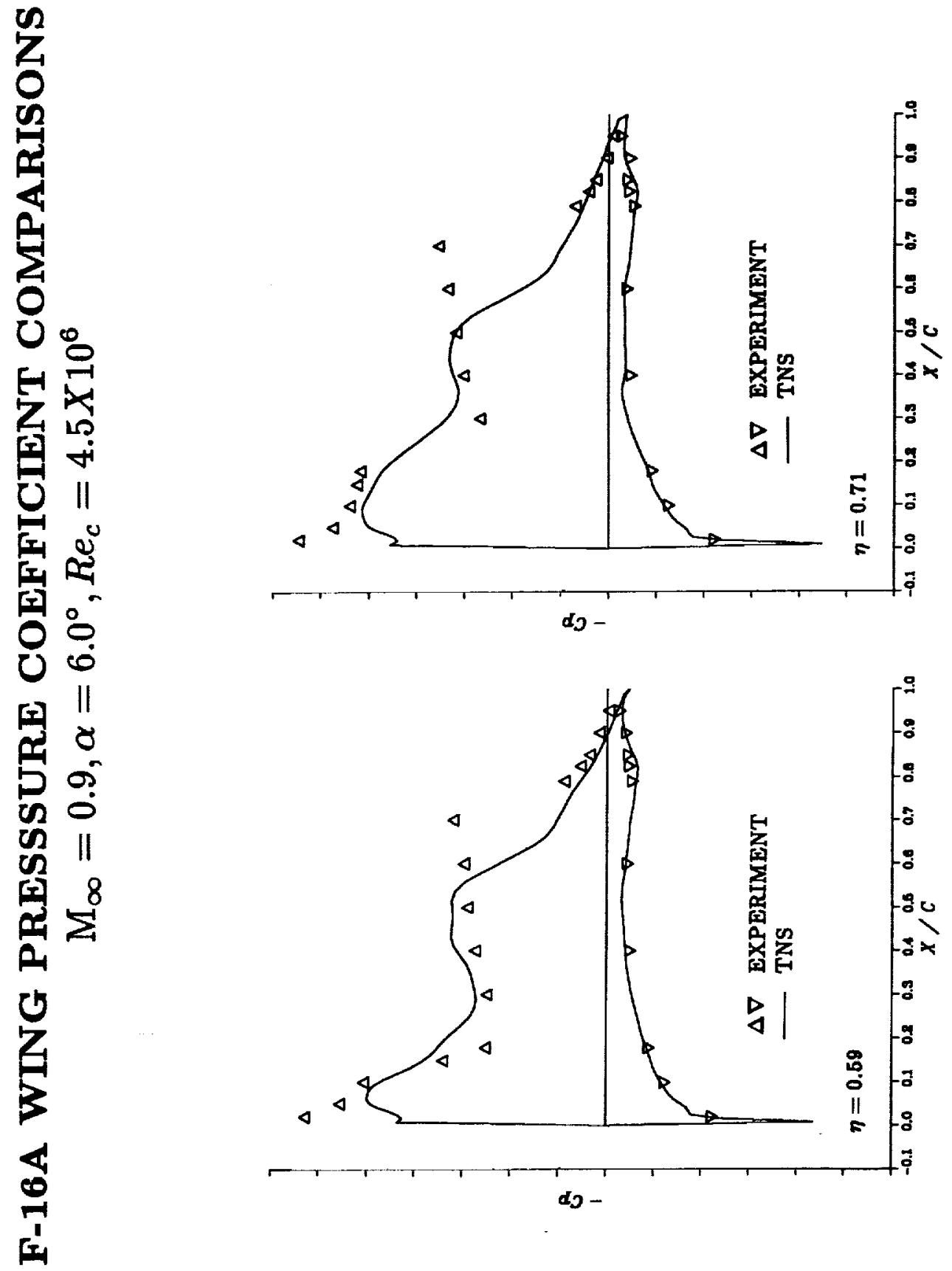

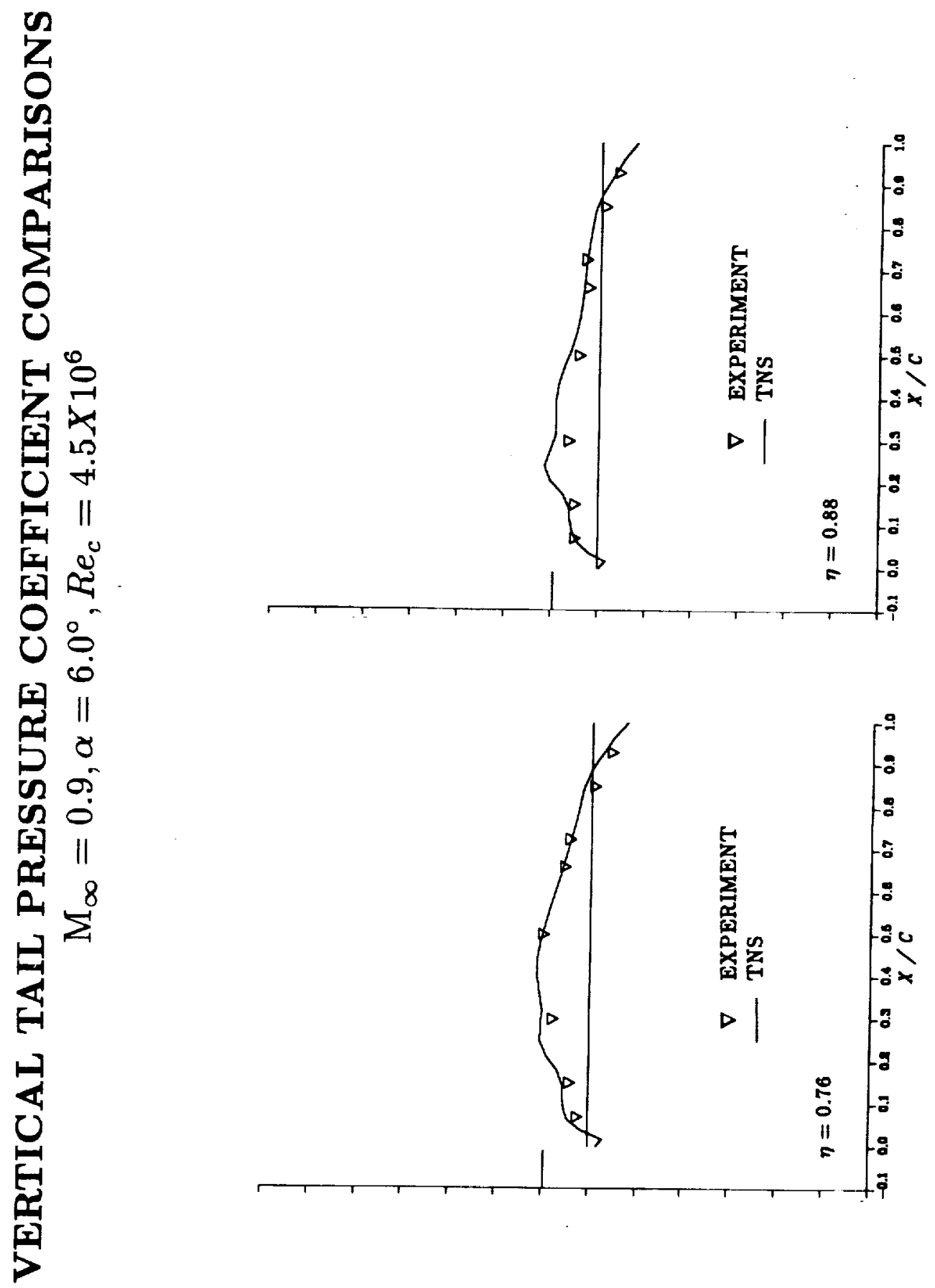

OREERS PRGE IS OF POOR QUALITY 

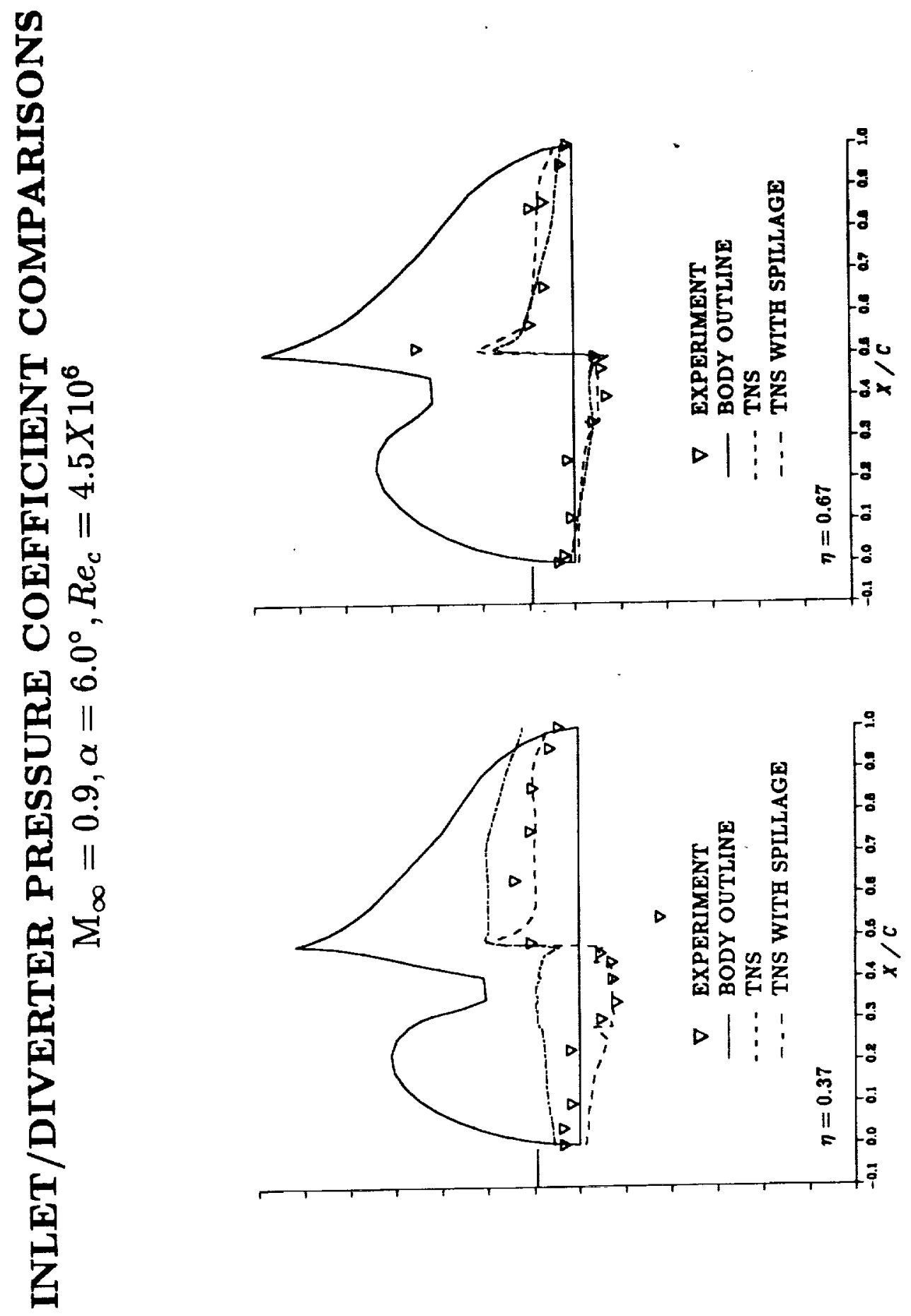

CWIMA PRE IS OF POSE GUALTY 

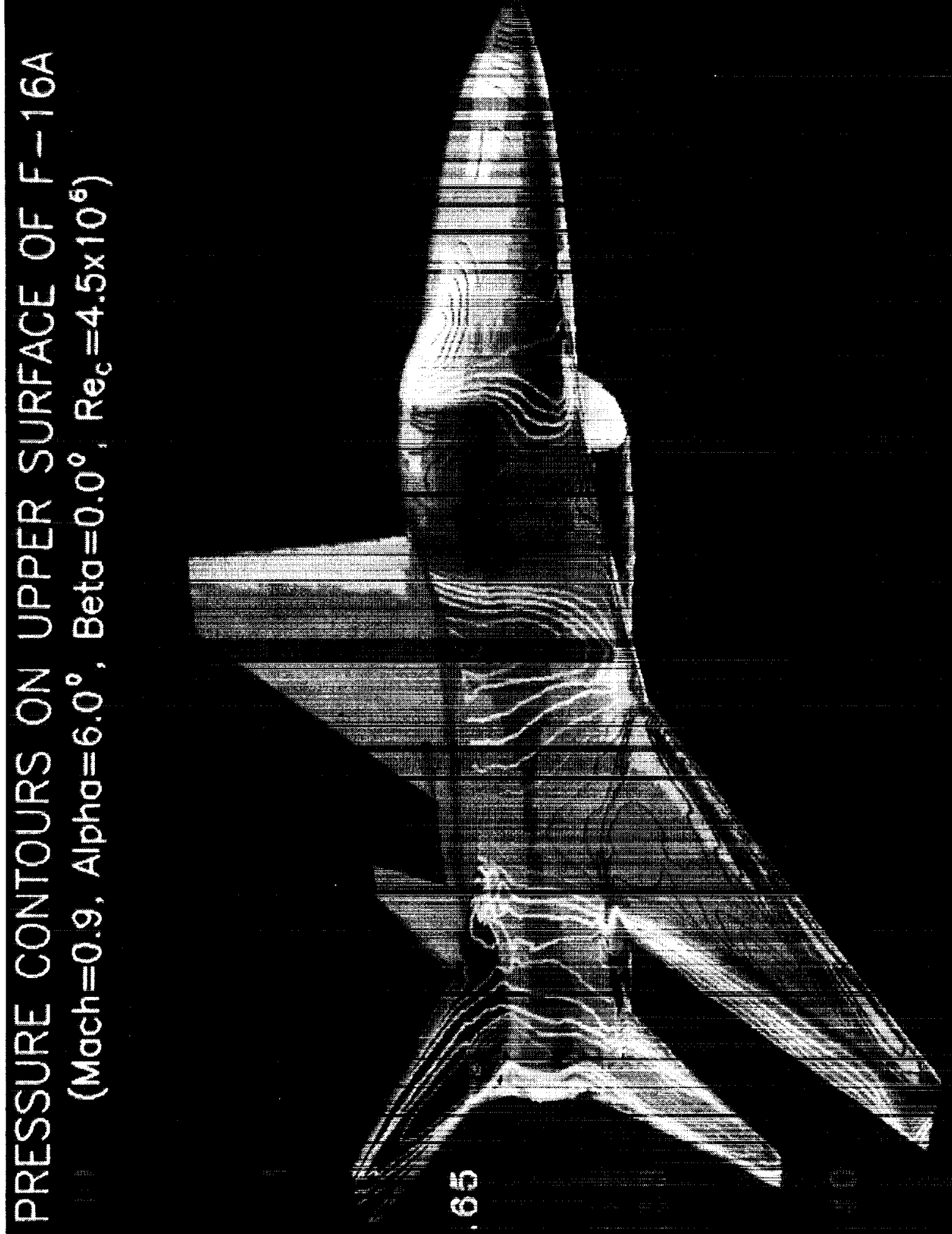


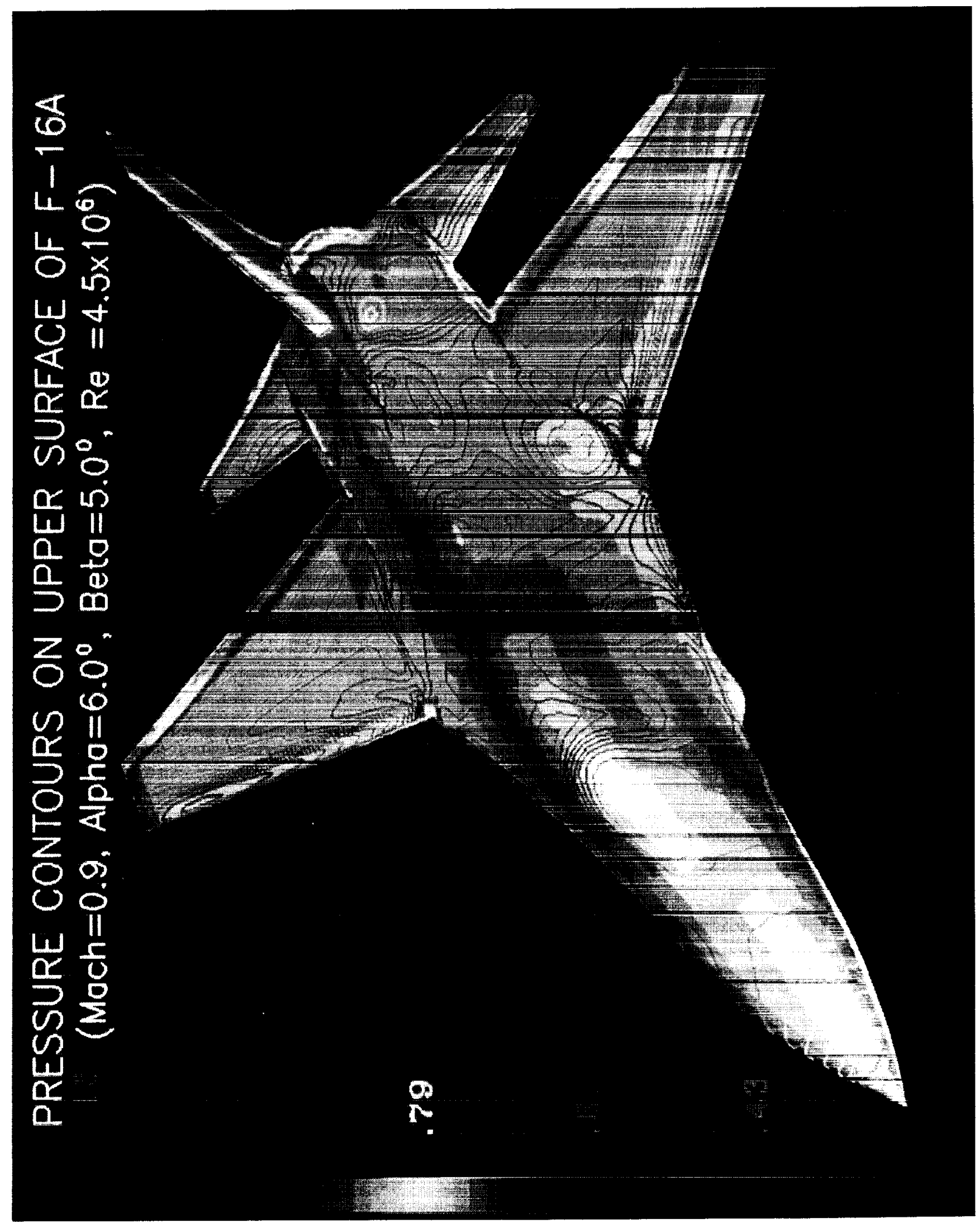

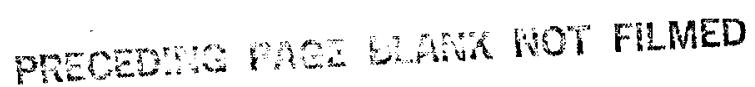




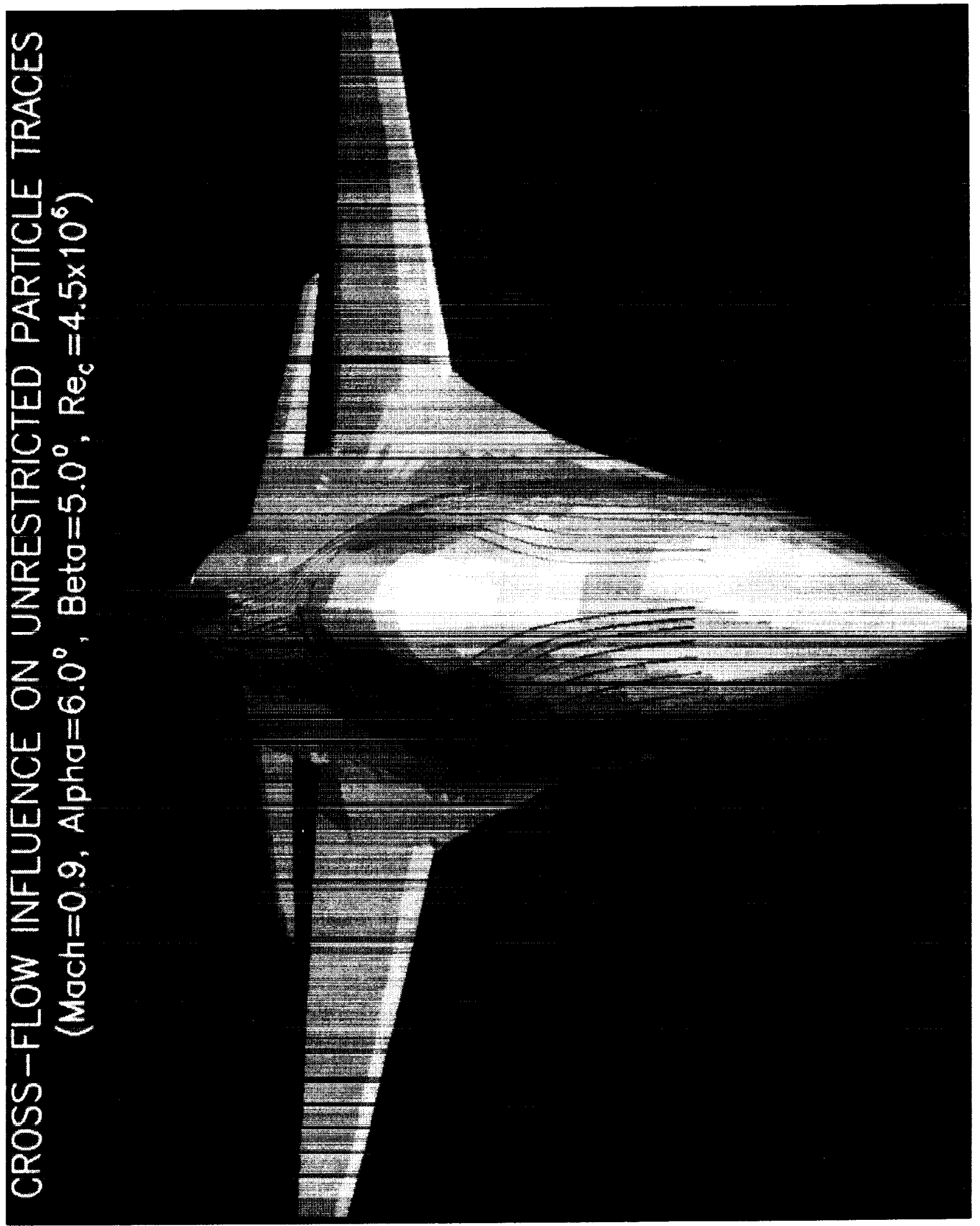


.....

$\ldots$ 


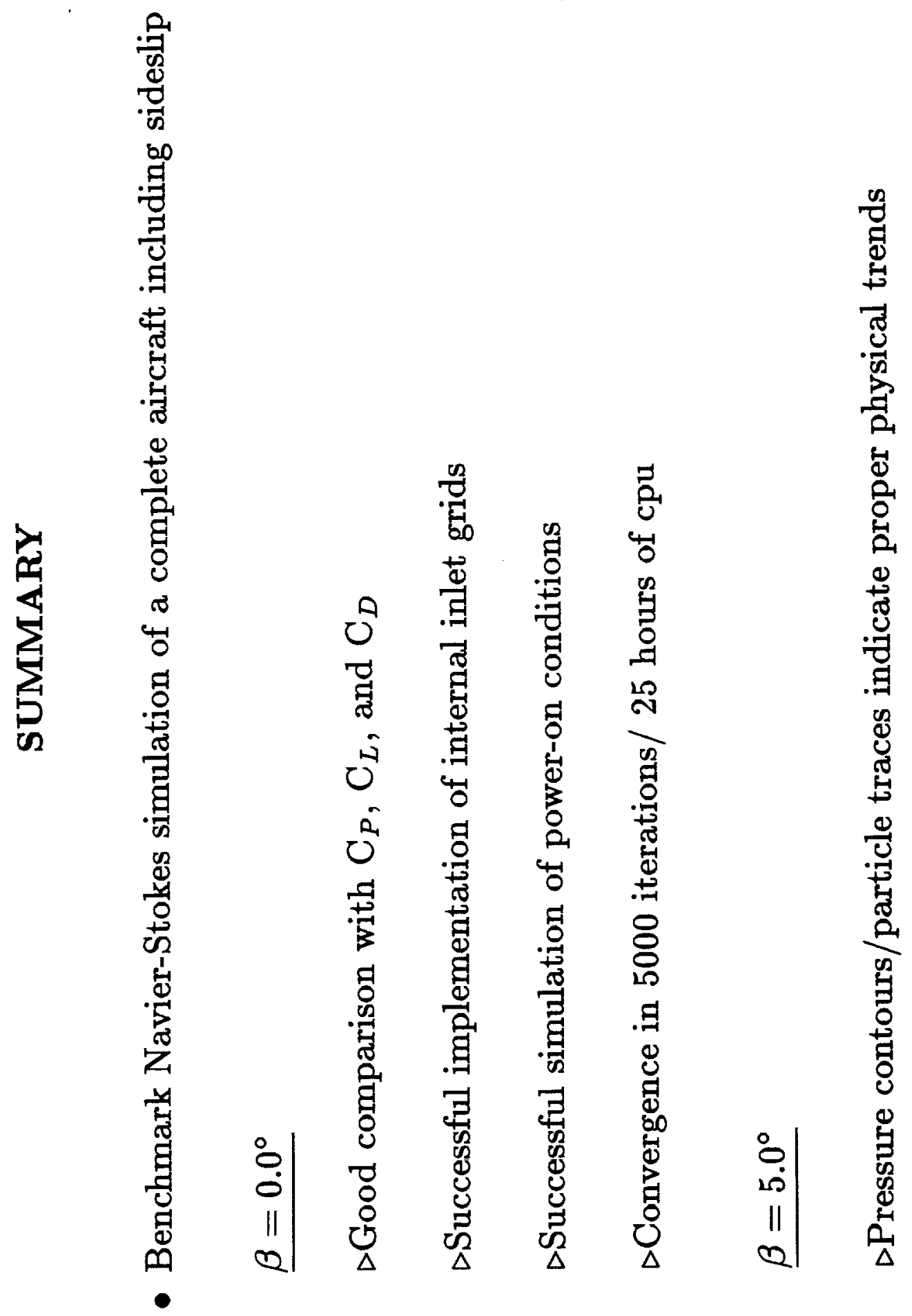


